\title{
Um Estudo De Caso Envolvendo A Aplicação De Um Software Educacional De Geometria Espacial
}

\author{
A Case Study Involving The Application Of An Educational Space \\ Geometry Software
}

\author{
Adriana Tederke Volpatto \\ Universidade Federal de Santa Maria - (UFSM) \\ Patrícia Rodrigues Fortes \\ Universidade Federal de Santa Maria - (UFSM) \\ Sidnei Renato Silveira \\ Universidade Federal de Santa Maria - (UFSM)
}

\begin{abstract}
Resumo
Este artigo apresenta um estudo de caso na área de Educação Matemática, voltado à aplicação de um software educacional no estudo de tópicos de Geometria Espacial. O estudo de caso envolve o planejamento e a aplicação de atividades utilizando o software GeoGebra como apoio aos processos de ensino e de aprendizagem na disciplina de Matemática de uma turma de $3^{\circ}$ ano do Ensino Médio, em uma Escola Estadual de Ensino Fundamental e Médio localizada em Taquaruçu do Sul - RS. O estudo de caso foi validado por meio de observação e questionários destinados a professora e aos alunos que participaram da experiência. Os resultados advindos da realização das referidas atividades apontam aprimoramentos nos processos de ensino e de aprendizagem de tópicos de Geometria Espacial, via aplicação do software Geogebra, nas aulas de Matemática da turma que participou do estudo de caso.
\end{abstract}

Palavras-chave: Software Educacional. Geometria Espacial. Matemática.

\begin{abstract}
This paper presents a case study in the mathematics education area, facing the application of educational software in the study of topics of spatia lgeometry. The case study proposes the construction of a planning activities using the GeoGebra software to support the teaching and learning processes in Mathematics in a class of $3 \mathrm{rd}$ year of high school, in a state school of elementary and high school located in Taquaruçu do Sul - RS. The case study will be validated through observation and questionnaires for the teacher and students. The results of these activities point out improvements in the teaching and learning of topics in Geometry, using Geogebra software, in the Mathematics classes of the class that participated in the case study.
\end{abstract}

Keywords: Educational Software. Spatial Geometry. Mathematics. 


\section{Introdução}

Os processos de ensino e de aprendizagem de conteúdos na área da Matemática estão se tornando cada vez mais desafiadores nos dias de hoje, já que, com tantas tecnologias disponíveis, os alunos não se motivam a participar de forma ativa das aulas tradicionais. Dessa forma, a busca pela motivação educacional é uma prática cada vez mais constante entre os professores (MORAIS, 2003).

Neste contexto, este artigo apresenta um trabalho que teve, por objetivo principal, realizar um estudo de caso voltado a alunos de $3^{\circ}$ ano do Ensino Médio, envolvendo a aplicação de um software educacional - o GeoGebra - no estudo de tópicos de Geometria Espacial. A Geometria Espacial - tema escolhido para o desenvolvimento do estudo de caso - é estudada em turmas de Ensino Médio, mais especificamente no $3^{\circ}$ ano, fase da vida na qual os alunos estão reconhecendo suas áreas profissionais preferidas, para então decidirem sobre o curso de graduação que farão no futuro.

Em nossa região (Região do Alto Médio Uruguai - RS) possuímos poucas informações sobre o uso de Tecnologias da Informação e da Comunicação (TICs) aplicadas aos processos de ensino e de aprendizagem, sendo as mesmas pouco utilizadas pelos professores, pelo fato de não possuírem o conhecimento necessário para tal aplicabilidade. Pretendemos, neste sentido, contribuir para ampliar o uso das TICs na região, por meio da aplicação de um software educacional, voltado ao ensino de Geometria Espacial. Escolhemos a Matemática (em especial a Geometria Espacial) por ser uma área muitas vezes abordada de forma teórica em sala de aula, cuja metodologia de ensino acaba se tornando muito difícil de ser empregada, pois são conteúdos complicados e cansativos de se trabalhar.

Ao definir o foco do estudo de caso, fizemos contato com uma Escola Estadual de Ensino Fundamental e Médio da região de abrangência da UFSM - Campus de Frederico Westpahlen, localizada na cidade de Taquaruçu do Sul - RS. A maior motivação para realização deste projeto foi a possibilidade de poder proporcionar ao público-alvo um cenário distinto do que eles vivenciam atualmente, já que poderemos agregar conhecimentos tecnológicos tanto para professores, quanto para alunos.

\section{Informática Na Educação E Software Educacional}

A aplicação dos recursos de Informática na Educação surgiu para revolucionar as metodologias convencionalmente utilizadas, em que o professor é o agente ativo e o aluno 
passivo; tal prática de ensino faz com que o aluno tenha um desequilíbrio em seu rendimento, já que o educando não participa como sujeito ativo do processo (MORAIS, 2003).

O uso dos computadores nos processos de ensino e de aprendizagem possibilita motivação ao professor, proporcionando um ensino mais dinâmico aos alunos. Porém, toda e qualquer ação a ser realizada no ambiente escolar deve possuir um plano pedagógico, com previsão de que, na matéria específica, seja aplicado o uso do computador no desenvolvimento do conteúdo a ser estudado, para que essa ferramenta possa ser útil e viável e não se torne um impasse no ensino (SILVA, et al., 2013).

A aplicação da Informática como apoio aos processos de ensino e de aprendizagem pode ser realizada por meio da utilização de diversos softwares, tais como editores de texto, jogos educacionais digitais, simuladores, entre outros. Qualquer software que seja utilizado como apoio aos processos de ensino e de aprendizagem pode ser considerado um software educacional.

Os Softwares Educacionais foram criados com o objetivo de auxiliar nos processos de ensino e de aprendizagem, fazendo com que os educandos iniciem ou aprimorem seus conhecimentos, tanto de informática como das áreas do conhecimento em que os softwares forem inseridos. O que diferencia um software educacional dos demais é o fato dele ter sido desenvolvido com o propósito de apoiar o ensino e a aprendizagem e não apenas para diversão (MORAIS, 2003).

Os softwares e as TICs permitem aumentar a possibilidade de os alunos construírem conhecimento. Acreditamos que a interação propiciada pelas TICS permita o desenvolvimento de habilidades diferenciadas. Neste trabalho, estudaremos a Geometria Espacial, cujos tópicos de estudo, tal como afirmado por Silva (2013), são muitas vezes enfocados em sala de aula a partir de estudos teóricos, com poucas atribuições de atividades práticas. Com a aplicação de um software educacional, acreditamos que os estudantes conseguirão entender realmente a visão espacial que este conteúdo deve mostrar.

A utilização de softwares educacionais no ensino da Matemática possibilita aos alunos uma visão distinta do conteúdo visto de maneira teórica em sala de aula. A partir destes contatos com a Informática, os alunos criam indagações dos conteúdos e sentem-se atraídos a investigar respostas para as atividades. A aplicação destes softwares torna-se um recurso lúdico de ensino, instigando os alunos a buscar mais informações sobre o assunto abordado. 


\section{Detalhamento Do Estudo De Caso Desenvolvido}

Por meio de um estudo de caso buscamos elaborar um plano para aplicação de um software educacional voltado à área de Matemática, mais especificamente ao ensino de Geometria Espacial. A aplicação do software educacional foi realizada com uma turma do $3^{\circ}$ ano do Ensino Médio, em uma Escola Estadual de Ensino Fundamental e Médio da cidade de Taquaruçu do Sul - RS.

Nosso projeto compreendeu a realização de um estudo de caso por meio do uso de um software educacional para promover o ensino de tópicos de Geometria Espacial. Segundo Yin (2001), os estudos de caso são uma metodologia de pesquisa adequada quando se colocam questões do tipo "como" e "por que". Tais indagações fazem parte do objetivo gerador deste trabalho. Yin (2001) ainda coloca que os estudos de caso podem ser usados para diversos tipos de pesquisas entre elas política, pesquisa em administração pública, sociologia, estudos em organizações e gerenciais, pesquisas em planejamentos regionais, dissertações e teses em ciências sociais, áreas profissionais como administração empresarial, entre outras.

O objetivo principal deste trabalho foi o de proporcionar a inclusão de ferramentas tecnológicas nos processos de ensino e de aprendizagem, que poderão ser estendidas após a realização deste estudo de caso trazendo, assim, resultados positivos para alunos e professores.

\subsection{Softwares Educacionais Estudados}

Para compor a proposta de trabalho optamos por realizar a análise dos softwares Calques 3D, Poly Pro, Wingeom e GeoGebra, justamente por serem aplicáveis à Geometria Espacial e também por serem disponibilizados gratuitamente. Vale ressaltar que estes softwares são programas interativos que permitem a criação e manipulação de figuras geométricas a partir de suas propriedades, sendo que são capazes de realizar as construções geométricas que podem ser feitas com régua e compasso, porém, não mais com o contexto estático de um caderno de desenho, mas sim na tela interativa de um computador. A Geometria proporcionada por programas gráficos como os softwares citados passou a ser denominada Geometria Dinâmica, contudo, tal denominação não deve ser vista como referência a uma nova Geometria (GRAVINA, 1996).

- Calques 3D: O Calques 3D é um software gratuito, destinado à Geometria Espacial. 
Quando as construções das figuras tridimensionais são feitas no Calques $3 D$ elas podem ser movimentadas, proporcionando muita interação com o usuário do software. Após realizada a construção das figuras, pontos, retas, planos, cilindros e esferas podem ser deslocados na tela mantendo-se as relações geométricas (pertinência, paralelismo, etc.) previamente estabelecidas, permitindo assim que o aluno (ou o professor), ao invés de gastar o seu tempo com detalhes de construção repetitivos, se concentre na associação existente entre os objetos. Uma mesma cena pode ser visualizada de ângulos diferentes, permitindo assim que o usuário tenha uma melhor percepção tridimensional (BORTOLOSSI; BASTOS, 2009).

- Poly Pro: O Poly Pro também é um software gratuito e destinado ao ensino da Geometria Espacial, que facilita a visualização de figuras em 3D e 2D, sendo uma ferramenta simples de usar, já que seus comandos e menus são bem intuitivos. O software permite visualizar uma classe de poliedros fazendo algumas operações, tais como, planificar, girar e salvar como GIF animado, imprimir o desenho tanto em $3 \mathrm{D}$ quanto planificado em $2 \mathrm{D}$. $\mathrm{O}$ software permite uma vasta investigação de sólidos, com possibilidade de movimento, por planificação e com vista topológica, além de possuir uma grande coleção de sólidos platônicos e arquimedianos (GRUPO GAUSS, 2010)

- Wingeom: O Wingeom também é um software gratuito e permite construções geométricas em 2D e 3D. O software permite a construção de figuras geométricas bastante precisas em duas ou três dimensões, as quais podem ser modificadas e animadas. Além disso, ele é um programa de fácil utilização, de modo que pode atender as necessidades tanto de professores na elaboração de suas propostas de trabalho pedagógico, quanto de alunos no aprofundamento de conteúdos abordados em sala de aula ou na realização de atividades educativas complementares. (RICHIT, et al. 2008).

- GeoGebra: Assim como os demais softwares citados anteriormente, o GeoGebra, também é gratuito, podendo ser aplicado nos processos de ensino e de aprendizagem nas disciplinas de Geometria, Álgebra e Cálculo. Este software permite a criação de figures em 2D e 3D. O GeoGebra é um sistema de geometria dinâmica que permite realizar construções com pontos, vetores, segmentos, retas, seções cônicas e funções que podem ser modificadas dinamicamente. Este software permite uma grande interação dos usuários, pois possibilita a criação de figuras geométricas planas e espaciais, com ampla visualização de pontos, vértices, faces e arestas (SOUZA, 2010). 


\subsection{Escolha pelo Software GeoGebra}

Salientamos que, apesar de algumas diferenças, o princípio básico de funcionamento dos softwares Calques 3D, Wingeom e GeoGebra é praticamente o mesmo, de forma que uma atividade desenvolvida com um deles pode facilmente ser executada em qualquer dos outros dois. Ainda, estes três softwares possibilitam movimentos, animações, visões laterais e frontais das figuras construídas pelo usuário do software - atributos da denominada Geometria Dinâmica. Já o software Poly Pro, apesar de ser visualmente muito atrativo (em função das cores, movimentos, planificações), somente permite que o usuário observe uma grande classe de poliedros, contudo, não permite construções.

O software escolhido para a realização deste trabalho foi o GeoGebra, pelo fato de atender a demanda proposta para esse estudo de caso e, também, por apresentar uma interface que acreditamos que facilita a interação entre o professor e os alunos.

O software GeoGebra foi o escolhido para o estudo de caso justamente porque favorece a construção de figuras geométricas (planas e espaciais) e a movimentação dos elementos dessas figuras, alterando formatos e medidas de forma dinâmica. Assim, o aluno pode perceber as relações existentes entre os elementos dessas figuras e constatar propriedades, facilitando a assimilação dos conceitos e definições referentes a essas figuras geométricas.

Depois de termos escolhido trabalhar com o software Geogebra, e para validar o estudo de caso proposto, elaboramos atividades voltadas ao conteúdo da Geometria Espacial, com colaboração da professora da escola onde foi realizado o estudo de caso, objetivando fazer com que os alunos reconheçam diferentes formas geométricas por meio do software educacional Geogebra.

\subsection{Atividades voltadas ao Ensino de Geometria Espacial}

O software Geogebra foi integrado ao plano de aula previsto pela professora. A aplicação do software foi realizada após a explicação teórica dos conteúdos de Geometria Espacial, sendo que os alunos foram encaminhados ao laboratório de informática da escola para resolver atividades definidas pela professora, com o emprego do referido software.

As atividades realizadas no laboratório foram divididas em seis tópicos, sendo que cada tópico se estendeu por três períodos de aula. Usamos o laboratório de informática da escola, onde há 16 computadores, com sistema operacional Linux. A turma que participou do estudo de 
caso cursa o $3^{\circ}$ ano do Ensino Médio, em turno noturno, e é composta por 8 alunos, com idades entre 16 e 21 anos:

- Tópico 1: Apresentação do Software Geogebra: O primeiro tópico do plano de atividades previstas, envolvendo a apresentação do software GeoGebra, ocorreu ainda no ambiente da sala de aula. Percebemos que os alunos mostraram-se pouco interessados na proposta de se trabalhar com um software na disciplina de Matemática. Acreditamos que a falta de interesse demonstrada naquela ocasião foi em função de que os alunos não chegaram a trabalhar diretamente com o software GeoGebra, pois apenas lhes foi apresentada a ferramenta por meio de slides, com explicações de que eles participariam (voluntariamente) de um estudo de caso, associado à elaboração de um trabalho de conclusão de curso de graduação;

- Tópico 2: Construção de Cubos: No $2^{\circ}$ encontro realizado com os alunos foram trabalhadas atividades de iniciação ao uso do software GeoGebra, no laboratório de informática da escola. Neste momento foram realizadas tarefas básicas de desenho geométrico, para que os alunos compreendessem algumas propriedades das figuras geométricas de forma interativa, por meio da manipulação de ferramentas e comandos do software. Neste mesmo encontro trabalhamos com prismas, mais especificamente com o traçado de cubos. Para tanto, fizemos inicialmente uma pequena retomada da definição que havia sido estudada em sala de aula sobre este hexaedro regular. Houve grande expectativa por parte dos alunos em termos das atividades que iriam realizar no laboratório de informática. Todos se interessaram em construir os objetos tridimensionais, inclusive, um dos alunos que possuía notebook em sala de aula solicitou a instalação do referido software em sua máquina para que, mesmo em horário extraclasse, ele pudesse utilizar o GeoGebra. A construção de um cubo, por exemplo, foi inicializada por meio de pontos discriminados como: "A", "B", "C" e "D", situados no plano xy (Janela de Visualização 2D). Após este procedimento iniciamos o processo de construção de um cubo na Janela 3D do software, onde há a opção de desenhar um cubo partindo da base já definida na Janela 2D. A Figura 1 mostra os esboços da construção de um cubo de aresta igual a 3 unidades de medida. 




Figura 1: Esboço Gráfico de um Cubo no Software GeoGebra Fonte: os autores

- Tópico 3: Construção de Tetraedros: No terceiro tópico do plano de atividades, realizamos a construção de tetraedros no Geogebra. Antes de iniciar a construção de um tetraedro no software GeoGebra, fizemos uma revisão (oral) do conceito que define este sólido geométrico, enfatizando que um tetraedro é um poliedro composto por quatro faces triangulares, três delas encontrando-se em cada vértice. Ainda, lembramos aos alunos que o tetraedro regular é um sólido platónico, figura geométrica espacial formada por quatro triângulos equiláteros (triângulos que possuem lados com medidas iguais); possui 4 vértices , 4 faces e 6 arestas. Para a construção de um tetraedro no software GeoGebra efetuamos basicamente os mesmos passos da construção dos cubos, ou seja, primeiramente esboçamos um triângulo equilátero na Janela de Visualização 2D e após efetuamos a visualização na Janela 3D, como mostra a Figura 2;

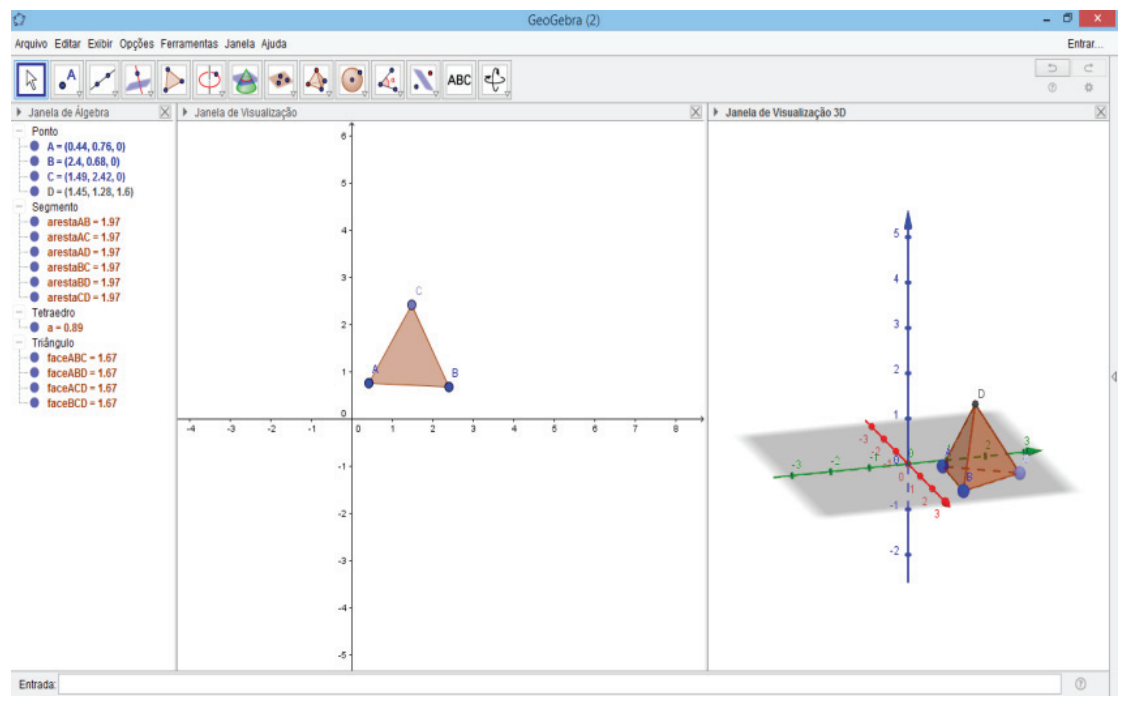

Figura 2: Visualização de um Tetraedro Regular no Software GeoGebra Fonte: os autores 
- Tópico 4: Construção de Pirâmides: Primeiramente efetuamos a escolha da região poligonal que deve caracterizar a base da pirâmide (base triangular, quadrangular, pentagonal, hexagonal). Desenhamos, então, a base na Janela de Visualização 2D e, em seguida, direcionamos o esboço para a janela de visualização 3D. Depois fizemos a extrusão da pirâmide para assim obter sua altura. Na Figura 3 apresentamos a imagem de uma pirâmide pentagonal construída no software GeoGebra;

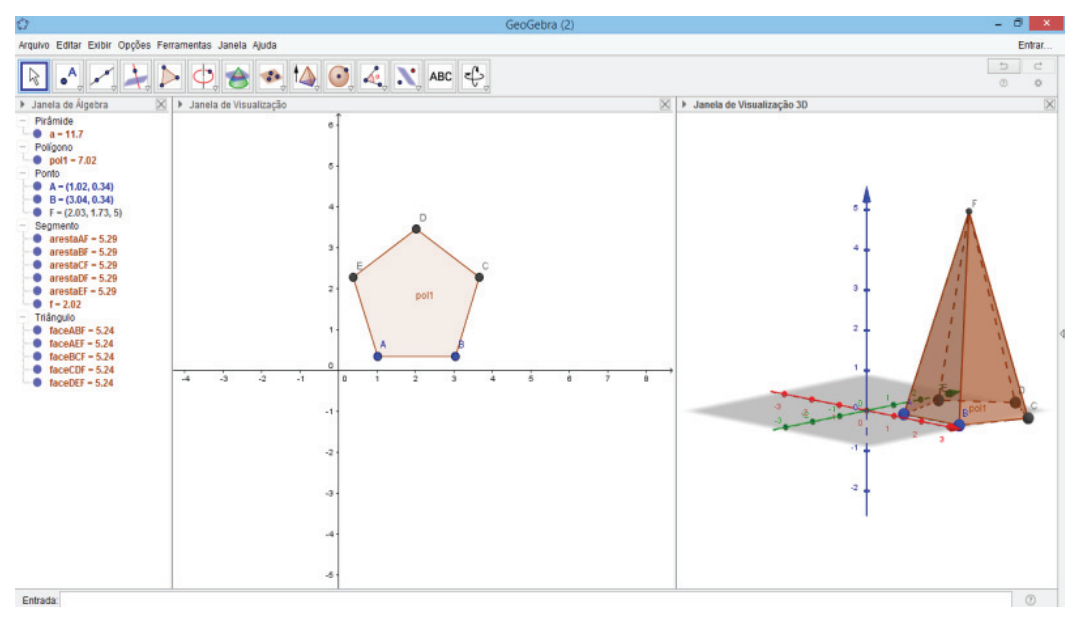

Figura 3: Pirâmide Pentagonal Construída no Software GeoGebra Fonte: os autores

- Tópico 5: Construção de Cones: Os passos utilizados para a construção de um cone foram os mesmos que realizamos na obtenção da pirâmide, porém, devido às características dos elementos de um cone, ao invés de utilizarmos um polígono regular utilizamos a ferramenta "Círculo dados centro e um de seus pontos" para definir a base do cone na janela de visualização plana, e após fizemos a extrusão do objeto na Janela de Visualização 3D, como mostra a Figura 4.

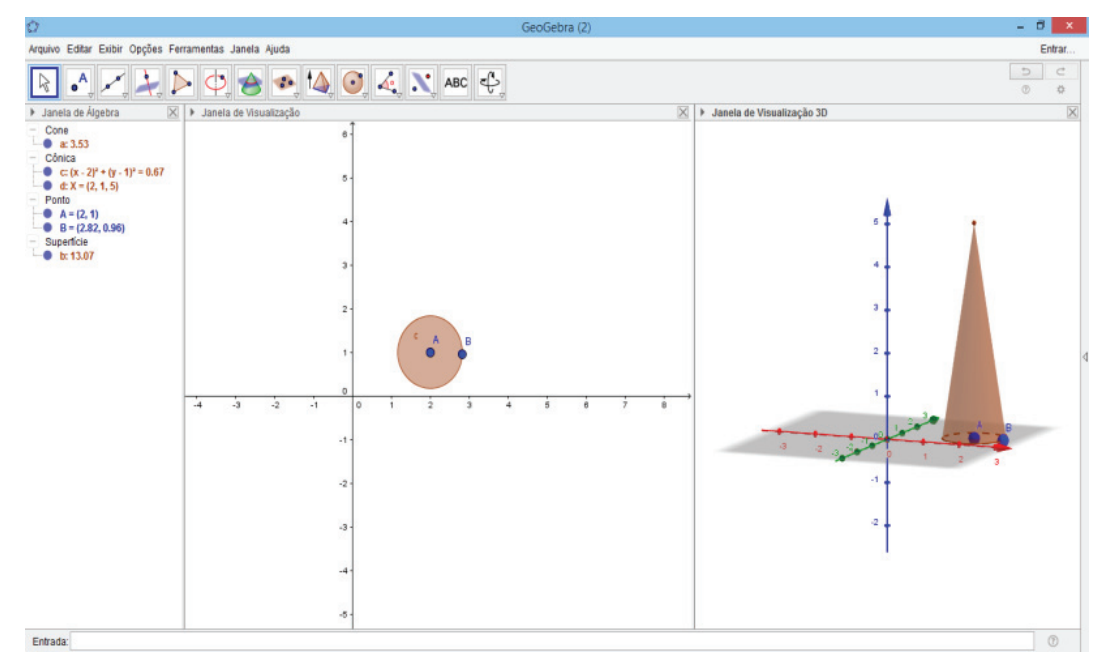

Figura 4: Exibição de um Cone Circular Reto no Software GeoGebra Fonte: os autores 
- Tópico 6: Construção de Cilindros e Esferas: No último encontro com os alunos realizamos a construção de esferas e cilindros, ambos realizados apenas na Janela de Visualização 3D, devido ao pouco tempo que tínhamos para trabalhar, pois a professora da turma iria trabalhar outros tópicos da disciplina, em sala de aula, logo após ao término da atividade que estávamos realizando no Laboratório de Informática. Sendo assim, tais corpos redondos não foram trabalhados diretamente a partir de pontos no plano e sim com visualizações já no espaço tridimensional. A atividade realizada é apresentada na Figura 5.

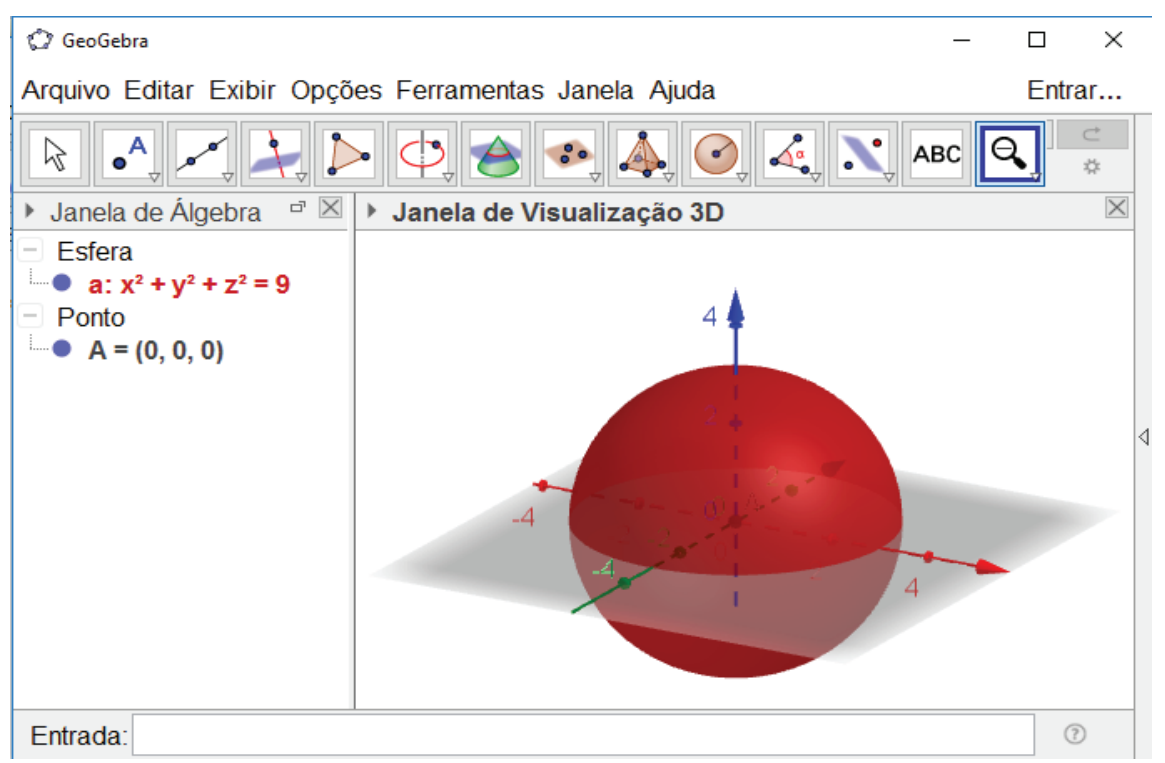

Figura 5: Esboço de uma Esfera no Software GeoGebra Fonte: os autores

Ao final da atividade realizada neste dia, aplicamos um questionário para os alunos e para a professora que acompanhou o estudo, visando coletar as opiniões dos mesmos sobre a utilização do software GeoGebra.

\subsection{Tabulação dos Dados e Discussão dos Resultados}

Os instrumentos de pesquisa utilizados neste estudo de caso envolveram questionários destinados à professora e aos alunos da turma, além de um roteiro de observação utilizado pelos pesquisadores. A $1^{\mathrm{a}}$ pergunta apresentada no questionário para os alunos foi: "Os professores realizam, regularmente, atividades no Laboratório de Informática?". Dos sete alunos que responderam ao questionário, todos eles afirmaram que utilizam o laboratório mensalmente, porém apenas nas aulas de Seminário Integrado, pois nesta matéria eles fazem projetos acadêmicos, tais como artigos, e necessitam utilizar o laboratório para realizar pesquisas. 
A $2^{\mathrm{a}}$ pergunta foi: "Os demais professores, de outras disciplinas, já utilizaram outros softwares como forma de apoio às atividades desenvolvidas em sala de aula? Se sim, quais softwares foram utilizados?". Todos os alunos responderam que nunca haviam utilizado softwares em nenhuma outra matéria, porém que gostariam de ter atividades como as realizadas no estudo de caso para poder entender melhor as outras matérias.

$\mathrm{Na} 3^{\mathrm{a}}$ pergunta começamos a mencionar o software GeoGebra, para sabermos qual foi a percepção dos alunos em relação a este estudo de caso. A descrição da pergunta foi: "Você sentiu-se motivado em participar das atividades propostas com a utilização do software GeoGebra?". Novamente, todos os alunos responderam afirmativamente. Os alunos destacaram que se sentiram motivados e a justificativa foi pelo modo de ensino trabalhado, que despertou o interesse deles em realizar as atividades com o uso do software, que lhes serviu de auxílio para o entendimento do conteúdo.

As respostas obtidas na $4^{\text {a }}$ pergunta foram bem divididas. A pergunta foi: "Você sentiu dificuldades para desenvolver as atividades propostas com a utilização do software GeoGebra?". Dos 7 alunos que responderam ao questionário 3 marcaram a opção de que haviam sentido dificuldades em relação às atividades desenvolvidas com o software GeoGebra. Estes alunos justificaram a resposta indicando falta de prática de uso da ferramenta, além de que acharam que o software se apresenta um pouco complicado nos primeiros momentos de uso, quando os iniciantes estão tendo os primeiros contatos com tal tecnologia. Os demais 4 alunos responderam que não enfrentaram dificuldades, afirmaram que o software se mostrou interessante, e que tiveram curiosidade em utilizá-lo.

Nos resultados da $5^{\mathrm{a}}$ pergunta, "Com relação ao estudo de caso desenvolvido, você considera que a proposta é relevante para apoiar os processos de ensino e de aprendizagem na área da Matemática?". Tivemos unanimidade nas respostas, sendo que os sete alunos responderam de forma positiva. Em suas justificativas nos expuseram o quanto foi importante para eles esta experiência, pois facilitou o entendimento dos sólidos estudados na Geometria Espacial, interessando-lhes a buscar e praticar o conteúdo, conseguindo melhor visualização e identificação dos objetos.

A 6 a pergunta, "Quais os pontos positivos que você pode destacar com relação ao estudo de caso desenvolvido?", envolvia uma resposta descritiva e individual. Entretanto, ao analisarmos as respostas notamos que todos haviam respondido que os pontos positivos a serem destacados foram a evolução no entendimento do conteúdo, já que, com as atividades práticas no laboratório, eles se motivaram a participar mais das aulas e buscar conhecer mais sobre o 
conteúdo. Segundo os alunos, o conhecimento adquirido com a prática os fez entender e visualizar de forma diferente os conteúdos da matéria, pois muitos não entendiam teoricamente os conceitos de aresta, vértice e face, mas com o trabalho a partir do software GeoGebra conseguiram assimilar tais ensinamentos.

$\mathrm{Na}$ última pergunta realizada no questionário dos alunos, que tinha como descrição: "Quais os pontos a melhorar que você pode destacar com relação ao estudo de caso desenvolvido?", as respostas também foram individuais e descritivas, e os alunos aprovaram o trabalho desenvolvido. Entretanto, não fizeram críticas e nem apontaram o que poderia ser melhorado. Eles colocaram que pretendem continuar se esforçando e se aprofundando no estudo do conteúdo e aqueles que possuem acesso a computadores em casa descreveram que irão continuar usando o software GeoGebra para aprimorar seus conhecimentos matemáticos.

Além do instrumento aplicado com os alunos, realizamos um questionário para a professora responsável pela disciplina. Pudemos analisar que a professora sentiu-se segura para desenvolvermos o estudo de caso na turma selecionada e, segundo ela, os alunos desta turma possuem um pouco mais de dificuldade no aprendizado do que os da turma diurna da mesma disciplina. Analisando as suas respostas, verificamos que a aplicação do software trouxe benefícios para a aprendizagem, pois com a introdução dos recursos tecnológicos os alunos sentiram-se atraídos pelo conteúdo.

$\mathrm{Na} 1^{\mathrm{a}}$ pergunta do instrumento aplicado com a professora: "Os alunos realizam, regularmente, atividades no Laboratório de Informática?", a resposta dada foi que o laboratório de informática é usado de maneira esporádica. Para a $2^{\mathrm{a}}$ pergunta: “Os alunos já utilizaram outros softwares como forma de apoio às atividades desenvolvidas na sala de aula, especialmente na área de Matemática?", sua resposta foi que já havia usado o software GeoGebra para demonstração e esboço gráfico de funções, porém há algum tempo atrás e em uma turma de $1^{\circ}$ ano.

$\mathrm{Na} 3^{\mathrm{a}}$ pergunta: "Os alunos demonstraram interesse em participar das atividades propostas com a utilização do software Geogebra?", o retorno foi positivo, sua justificativa foi que o software é simples, fácil de ser utilizado e compreendido.

$\mathrm{Na} 4$ a pergunta: "Com relação ao estudo de caso desenvolvido, você considera que a proposta é relevante para apoiar os processos de ensino e de aprendizagem na área de Matemática?", a resposta dada pela professora foi positiva, pois segundo ela: "sempre que se agrega a prática à teoria, o conhecimento é contruído com mais solidez”.

Para a pergunta "Quais os pontos positivos que você pode destacar com relação ao 
estudo de caso desenvolvido?", a resposta dada foi: "Os pontos positivos que podemos destacar são as construções dos sólidos, afirmando conceitos e teorias, além da versatilidade e aplicabilidade do tema abordado".

Na sexta pergunta: "Quais os pontos a melhorar que você pode destacar com relação ao estudo de caso desenvolvido?", a professor destacou que o estudo de caso desenvolvido foi muito bem conduzido e explorado pelos pesquisadores, que demonstraram interesse em auxiliar os alunos com o seu conhecimento.

Com relação à $7^{\mathrm{a}}$ e última pergunta realizada à professora: “Após as atividades desenvolvidas com a utilização do software, os alunos sentiram-se mais motivados a participar das aulas?", a mesma colocou que "Com certeza os recursos tecnológicos sempre são muito atrativos aos jovens e consequentemente o que se aprende com prazer, não se esquece. Após o estudo de caso realizado, nós professores também nos sentimos motivados a mudar nosso cotidiano, e nos próximos anos iremos fazer uso de softwares para um ensino melhor".

\section{Considerações Finais}

O principal objetivo deste estudo de caso foi o de proporcionar maior inclusão de ferramentas tecnológicas nos processos de ensino e de aprendizagem de Matemática, mais especificamente em tópicos voltados à Geometria Espacial.

Durante o desenvolvimento do estudo de caso detalhamos os passos de realização de cada atividade perante aos alunos e percebemos o crescente envolvimento dos mesmos a cada aula, com atitudes curiosas para trabalhar com os comandos do software GeoGebra, sempre indo além do que lhes era solicitado.

Acreditamos que a realização do estudo ocasionou aumento de autoestima e motivação por parte dos alunos em querer participar das aulas de Matemática, tendo em vista aulas interativas e, para a professora, facilidade e agilidade para promover o ensino nas aulas de Matemática. Muitos alunos apresentam dificuldades de aprendizagem nesta matéria, sendo que a grande maioria trabalha o dia todo, e quando chegam na escola já estão exaustos. Com as atividades realizadas no software GeoGebra eles puderam participar ativamente na construção de seus conhecimentos, expondo suas dificuldades e superando-as, com auxílio da professora e dos pesquisadores.

A maior dificuldade que enfrentamos na efetivação das ações de desenvolvimento do estudo de caso foi a indisponibilidade de uso (por parte dos alunos) dos recursos tecnológicos 
em horário extraclasse, pois nem todos possuíam computadores em casa para que pudessem realizar atividades de manipulação do software GeoGebra.

Contudo, acreditamos que o uso do referido software aprimorou os processos de ensino e de aprendizagem dos tópicos de Geometria Espacial. A motivação dos alunos melhorou, pois eles demonstraram-se interessados em participar das aulas e a buscar novos conhecimentos relacionados aos tópicos estudados. Para o próximo ano a professora já fez planos para trabalhar a partir do software GeoGebra com turmas em que ela leciona, uma vez que já havia tido contato com este software anteriormente e já possuía um pouco de domínio de tal ferramenta, porém tinha receio em expor aos alunos e eles perderem o interesse nas aulas. Como visto neste estudo de caso, a reação deles é inversa ao que ela pensava. Sendo assim, no ano que vem, ela irá planejar e utilizar este recurso tecnológico visando obter melhores resultados no ensino de Matemática.

Concluímos, por meio deste estudo de caso, que a utilização do software GeoGebra trouxe resultados satisfatórios, pois a grande motivação apresentada pelos alunos permitiu uma participação ativa e, consequentemente, uma melhoria na aprendizagem. Para trabalhos futuros temos a pretensão de realizar o estudo de outros softwares de outras matérias e aplicá-los na escola.

\section{Referências}

BORTOLOSSI, H. J.; BASTOS, C. (2009) Calques 3D: Software de Geometria Dinâmica Espacial Gratuito. Disponível em: <www.uff.br/calques3d/calques3d.overview.html $>$. Acesso em junho, 2016.

GRAVINA, M. A. (1996) Geometria Dinâmica: uma nova abordagem para o Aprendizado de Geometria. VII Simpósio Brasileiro de Informática na Educação. Belo Horizonte, MG, Anais do VII SBIE, nov. Disponível em: <http://www2.mat.ufrgs.br/edumatec/artigos/a2.zip $>$. Acesso em junho, 2016.

GRUPO GAUSS (2010) Software PolyPro, Blog. Disponível em: <http://grupogauss.blogspot.com.br/2010/12/software-polypro.html>. Acesso em junho, 2016.

MORAIS, R. X. T. (2003) Software Educacional: a importância de sua avaliação e do seu uso nas salas de aula.Faculdade Lourenço Filho. Monografia. Disponível em: $<$ http://www.flf.edu.br/revistaflf/monografias-computacao/monografia-rommel-xenofonte.pdf $>$. Acesso em abril, 2016.

RICHIT, A., TOMKELSKI, M. L., RICHIT, A. (2008) Software Wingeome Geometria Espacial: explorando conceitos e propriedades. IV Colóquio de História e Tecnologia no Ensino da Matemática. Disponível em: <http://limc.ufrj.br/htem4/papers/26.pdf>. Acesso em junho, 2016.

SILVA, A. R. (2013) Uma proposta para o ensino de Geometria Espacial Métrica no Ensino Médio. Lavras: UFLA. Dissertação. Disponível em: $<$ http://repositorio.ufla.br/bitstream/1/787/1/DISSERTACAO_Uma\%20proposta $\% 20$ para $\% 20 \mathrm{o} \% 20 \mathrm{en}$ 
sino\%20da\%20geometria....pdf $>$. Acesso em abril, 2016.

SILVA, M. F; CORTEZ, R. C. C.; OLIVEIRA, V. B. (2013) Software Educativo como auxílio na aprendizagem da matemática: uma experiência utilizando as quatro operações com alunos do $4^{\circ}$ Ano do Ensino Fundamental I. Educação, Cultura e Comunicação, Fatea, V.4, n.7. Disponível em: $<$ http://publicacoes.fatea.br/index.php/eccom/article/viewFile/594/424>. Acesso em abril, 2016.

SOUZA, J. C. (2010) Introdução ao GeoGebra. Tutorial. Disponível em: <http://www.unifalmg.edu.br/matematica/files/file/JOSE-CARLOS/Tutorial.pdf>. Acesso em junho, 2016.

YIN, R. K. (2001) Estudo de Caso: planejamento e métodos.2. ed. Porto Alegre: Bookman 